\title{
Genome-wide identification of small heat- shock protein (HSP20) gene family in grape and expression profile during berry development
}

\author{
Xiao-Ru Ji ${ }^{1,2}, Y_{i-H e ~ Y u^{1,2}}$, Pei-Yi Ni ${ }^{1,2}$, Guo-Hai Zhang ${ }^{1}$ and Da-Long Guo ${ }^{1,2^{*}}$ (D)
}

\begin{abstract}
Background: Studies have shown that HSP2O (heat-shock protein 20) genes play important roles in regulating plant growth, development, and stress response. However, the grape HSP2O gene family has not been well studied.

Results: A total of 48 VVHSP2O genes were identified from the grape genome, which were divided into 11 subfamilies (Cl, Cll, CIII, CV, CVI, CVII, MI, MII, ER, CP and PX/Po) based on a phylogenetic analysis and subcellular localization. Further structural analysis showed that most of the VVHSP2O genes (93.8\%) had no intron or only one intron, while genes that clustered together based on a phylogenetic tree had similar motifs and evolutionarily conserved structures. The HSP20s share a conserveda-crystalline domain (ACD) and the different components of the ACD domain suggest the functional diversity of VVHSP20s. In addition, the 48 VVHSP2O genes were distributed on 12 grape chromosomes and the majority of VVHSP2O genes were located at the proximal or distal ends of chromosomes. Chromosome mapping indicated that four groups of VVHSP2O genes were identified as tandem duplication genes. Phytohormone responsive, abiotic and biotic stress-responsive, and plant development-related cis-elements were identified from the cis-regulatory elements analysis of VvHSP20s. The expression profiles of VVHSP20s genes (VVHSP20-1, 11, 14, 17, 18, 19, 20, 24, 25, 28, 31, 39, 42, and 43) were largely similar between RNASeq and qRT-PCR analysis after hydrogen peroxide $\left(\mathrm{H}_{2} \mathrm{O}_{2}\right)$ treatment. The results showed that most VVHSP2Os were down-regulated by $\mathrm{H}_{2} \mathrm{O}_{2}$ treatment during fruit development. VVHSP2Os genes were indeed found to be involved in the grape berry development and differences in their transcriptional levels may be the result of functional differentiation during evolution.
\end{abstract}

Conclusions: Our results provide valuable information on the evolutionary relationship of genes in the VVHSP2O family, which is useful for future studies on the functional characteristics of VVHSP2O genes in grape.

Keywords: Grape, HSP20, Gene family, Genome-wide analysis, $\mathrm{H}_{2} \mathrm{O}_{2}$

\section{Background}

As one of the most important cultivated fruit crops in the world, grape has high economic value. 'Kyoho' is a tetraploid interspecific hybrid and mid-late ripening grape cultivar derived from a cross between Vitis vinifera $\mathrm{x}$ Vitis labrusca, which is widely cultivated in China. Our previous studies on 'Kyoho' have shown that hydrogen peroxide $\left(\mathrm{H}_{2} \mathrm{O}_{2}\right)$

\footnotetext{
* Correspondence: guodalong@haust.edu.cn

${ }^{1}$ College of Forestry, Henan University of Science and Technology, Luoyang 471023, Henan Province, China

${ }^{2}$ Henan Engineering Technology Research Center of Quality Regulation and Controlling of Horticultural Plants, Luoyang 471023, Henan Province, China
}

treatment could promote the early ripening of 'Kyoho' grape, causing it to ripen 20 days earlier than the control [1, 2]. Other studies in tomato [3] and pear [4] have also demonstrated that $\mathrm{H}_{2} \mathrm{O}_{2}$ is associated with fruit development. $\mathrm{H}_{2} \mathrm{O}_{2}$ is an early component of the thermal signal pathway, which is a necessary condition for the activation of heatshock protein 20 (HSP20) synthesis [5]. In addition, the response of HSP2Os to $\mathrm{H}_{2} \mathrm{O}_{2}$ has also been revealed in tomato and rice, where $\mathrm{H}_{2} \mathrm{O}_{2}$ was shown to induce the expression of mitochondrial HSP22 and chloroplast HSP26, respectively $[6,7]$. It has been reported that HSP21 could protect

(C) The Author(s). 2019 Open Access This article is distributed under the terms of the Creative Commons Attribution 4.0 International License (http://creativecommons.org/licenses/by/4.0/), which permits unrestricted use, distribution, and 
photosystem II (PSII) from oxidative stress, promote color change during fruit ripening, and play a key role in the transformation of chloroplasts to pigment mother cells during fruit ripening [8].

The expression of HSPs is activated or increased under high temperature stress. According to molecular weight and sequence homology, HSPs can be divided into five families, which include HSP100, HSP90, HSP70, HSP60, and HSP20 $[9,10]$. Among them, the molecular weights of HSP20 proteins are between 15 and $42 \mathrm{kDa}$, and are thus considered small HSPs. In some plant tissues, HSP20s comprise the largest proportion of HSPs [9]. HSP20s possess a typical conserved domain, known as the $\alpha$-crystalline domain (ACD), which contains a conserved 80-100 amino acid sequence, a compact $\beta$-strand structure, and two conserved regions (CRs): CR I with $\beta 2, \beta 3, \beta 4$, and $\beta 5$; and CR II with $\beta 7, \beta 8, \beta 9$, and a $\beta 6$ loop [11]. HSP20s can prevent the damage of proteins caused by environmental stress and help them to fold or degrade $[12,13]$. Thus, HSP20s are the important parts of cellular molecular chaperones.

In plants, HSP2O genes are involved in many developmental processes and responses to abiotic stresses [14, 15]. Under heat stress, HSP20s can prevent the aggregation and irreversible denaturation of heat-denatured proteins, which ensures that other proteins can perform normal functions at high temperature, providing a strong basis for improving the heat resistance of plant organs. HSP20s have been shown to be located in mitochondria, cytoplasm, and endoplasmic reticulum [16].

The number of HSP2O genes in plants is about four times greater than that in animals [17]. For example, 19, 35, 39, 42, 44, 51 members of the HSP20 gene family were respectively investigated in Arabidopsis (Arabidopsis thaliana) [11], pepper (Capsicum annuum L.) [18], rice (Oryza sativa) [19], tomato (Solanum lycopersicum) [20], watermelon (Citrullus lanatus L.) [21], and soybean (Glycine max) [22]. To date, HSP20 gene family members in grape have not been identified. Therefore, this study aims to elucidate the composition, gene structure, evolution, and expression of the grape HSP20 gene family, in an attempt to characterize structural and functional features, and to establish a foundation for further utilization of plant HSPs.

\section{Results}

\section{Genome-wide identification of $V v H S P 20$ gene family in grape}

A total of $61 V v H S P 20$ genes were obtained by Hidden Markov Model (HMM) analysis. The presence of an ACD domain was confirmed by submitting the protein sequences to CDD, Pfam, and SMART database. The sequences without the typical ACD domain were discarded. A total of 48 sequences were retained and confirmed as grape HSP20 after removing the sequences with a molecular weight beyond the $15-42 \mathrm{kDa}$. Detailed information on physicochemical properties of these HSP20s are listed in Table 1. The length of the VvHSP20 proteins varied from 136 (VvHSP20-47 and VvHSP20-48) to 365 amino acids (VvHSP20-41); the molecular weights of VvHSP20s were from $15.27 \mathrm{kDa}$ (VvHSP20-30) to $40.59 \mathrm{kDa}$ (VvHSP20-41). The predicted $\mathrm{pI}$ values of VvHSP20s ranged from 4.68 (VvHSP20-41) to 9.48 (VvHSP20-20).

\section{Phylogenetic analysis of $\mathrm{VvHSP20}$ genes}

An unrooted Neighbor-Joining (NJ) phylogenetic tree was constructed based on the alignment of amino acid sequences of HSP20 from grape, Arabidopsis, tomato (Fig. 1). In total, 19 sequences from Arabidopsis, 26 sequences from tomato, and 48 sequences from grape were assessed in the phylogenetic tree. According to the phylogenetic and the subcellular localization analysis, the grape HSP20 protein are divided into 11 subfamilies (CI, CII, CIII, CV, CVI, CVII, MI, MII, ER, CP, and PX/Po) (Fig. 1, Table 1). Clustering of the subfamilies in grape is largely consistent with the subcellular localization, i.e., the proteins in the same cluster were located in the same subcellular sites. Specifically, six HSP20 subfamilies (CI-CVI), MTI and MTII subfamilies, CP, ER and PX /Po localize to the cytoplasm/nucleus, mitochondria, chloroplast, endoplasmic reticulum and peroxisome, respectively. The $93 \mathrm{HSP} 20$ s were classified into 14 distinct subfamilies, except for the unclassified VvHSP20s (VvHSP20-15, VvHSP20-16, VvHSP20-38, and VvHSP20-41), the subcellular localization of which could not be predicted using the online tool Protcomp. Most of the VvHSP20s, including 33 out of 44, were classified into CI-CVII, which suggested that the cytosol may be the primary functional site of plant HSP20s.

\section{Characterization of the amino acid sequences and gene structure of VvHSP20s}

As shown in Fig. 2a, 48 VvHSP20s were divided into 11 subgroups, except for the unclassified HSP20 (VvHSP20-15, VvHSP20-16, VvHSP20-38 and VvHSP20-41). Ten conserved motifs of VvHSP20 proteins were identified by the MEME website and listed in Table 2. The lengths of these conserved motifs ranged from 6 to 60 amino acids (Fig. 2b, Table 2). ACD consists of two conserved regions, CRI of $\beta 2, \beta 3$ and $\beta 4$, and CRI of $\beta 7, \beta 8$ and $\beta 9$, separated by a variable length hydrophilic region $\beta 6$ loop (Fig. 3). VvHSP20-2, 3, 39, 40, 47 and 48 lacked the $\beta 6$-loop. VvHSP20-36 lacked the $\beta$-strands 4 . The different components of the ACD domain suggest functional diversity among VvHSP20s. The same group of VvHSP20 proteins in the phylogenetic tree 
Table 1 Features of VvHSP20 genes identified in grape

\begin{tabular}{|c|c|c|c|c|c|c|c|c|}
\hline Gene name & Sequence ID & ORF Length (bp) & $\mathrm{Chr}$ & Chromosome Position & Length (aa) & MW (KDA) & $\mathrm{pl}$ & ProtComp \\
\hline$\overline{H S P 20-1}$ & VIT_0150010g02290.t01 & 549 & 1 & $19,257,410-19,258,339$ & 182 & 20.74 & 5.42 & Chloroplast \\
\hline HSP2O-2 & VIT_02s0154g00480.t01 & 606 & 2 & $5,248,542-5,250,041$ & 201 & 22.45 & 9.24 & Mitochondrial \\
\hline HSP2O-3 & VIT_02s0154g00490.t01 & 606 & 2 & $5,255,141-5,256,154$ & 201 & 22.55 & 9.11 & Mitochondrial \\
\hline HSP2O-4 & VIT_0450008g01490.t01 & 471 & 4 & $1,219,942-1,220,465$ & 156 & 17.34 & 5.94 & Cytoplasmic \\
\hline HSP2O-5 & VIT_04s0008g01500.t01 & 459 & 4 & $1,221,915-1,222,579$ & 1521 & 16.69 & 6.84 & Cytoplasmic \\
\hline HSP2O-6 & VIT_04s0008g01510.t01 & 471 & 4 & $1,223,278-1,224,822$ & 156 & 17.40 & 5.77 & Cytoplasmic \\
\hline HSP2O-7 & VIT_04s0008g01520.t01 & 471 & 4 & $1,224,823-1,225,354$ & 156 & 17.58 & 5.58 & Cytoplasmic \\
\hline HSP2O-8 & VIT_04s0008g01550.t01 & 471 & 4 & $1,237,576-1,240,002$ & 156 & 17.41 & 5.94 & Cytoplasmic \\
\hline HSP2O-9 & VIT_04s0008g01570.t01 & 501 & 4 & $1,244,737-1,246,530$ & 166 & 18.60 & 5.95 & Cytoplasmic \\
\hline HSP2O-10 & VIT_04s0008g01580.t01 & 471 & 4 & $1,248,569-1,249,249$ & 156 & 17.42 & 6.62 & Cytoplasmic \\
\hline HSP2O-11 & VIT_04s0008g01590.t01 & 468 & 4 & $1,251,984-1,252,699$ & 155 & 17.29 & 5.94 & Cytoplasmic \\
\hline HSP2O-12 & VIT_0450008g01610.t01 & 477 & 4 & $1,255,490-1,256,222$ & 158 & 18.14 & 6.33 & Cytoplasmic \\
\hline HSP2O-13 & VIT_04s0008g01620.t01 & 480 & 4 & $1,257,262-1,257,741$ & 159 & 18.42 & 8.46 & Cytoplasmic \\
\hline HSP2O-14 & VIT_06s0004g05770.t01 & 435 & 6 & $6,524,201-6,524,870$ & 144 & 16.31 & 6.93 & Cytoplasmic \\
\hline HSP2O-15 & VIT_06s0009g01090.t01 & 948 & 6 & $12,540,124-12,542,550$ & 315 & 34.98 & 8.58 & - \\
\hline HSP2O-16 & VIT_08s0032g00100.t01 & 579 & 8 & $3,034,519-3,035,221$ & 192 & 21.52 & 8.45 & - \\
\hline HSP2O-17 & VIT_08s0058g00210.t01 & 447 & 8 & $8,901,763-8,902,216$ & 148 & 16.88 & 5.81 & Nuclear \\
\hline HSP20-18 & VIT_09s0002g00640.t01 & 483 & 9 & $440,684-441,359$ & 160 & 17.89 & 6.3 & Cytoplasmic \\
\hline HSP2O-19 & VIT_09s0002g06790.t01 & 702 & 9 & $6,710,140-6,711,133$ & 233 & 26.31 & 7.78 & Mitochondrial \\
\hline HSP2O-20 & VIT_12s0028g01390.t01 & 780 & 12 & $2,044,541-2,046,498$ & 259 & 28.71 & 9.48 & - \\
\hline HSP2O-21 & VIT_12s0035g01910.t01 & 753 & 12 & $22,228,715-22,229,897$ & 250 & 28.39 & 7.94 & Endoplasmic reticulum \\
\hline HSP2O-22 & VIT_13s0019g00860.t01 & 429 & 13 & $2,689,279-2,690,178$ & 142 & 15.81 & 6.75 & Peroxisomal \\
\hline HSP2O-23 & VIT_13s0019g02740.t01 & 456 & 13 & $3,999,388-4,000,084$ & 151 & 17.17 & 5.81 & Nuclear \\
\hline HSP2O-24 & VIT_13s0019g02760.t01 & 423 & 13 & $4,003,325-4,003,954$ & 140 & 15.8 & 6.77 & Cytoplasmic \\
\hline HSP2O-25 & VIT_13s0019g02770.t01 & 456 & 13 & $4,006,363-4,007,091$ & 151 & 17.1 & 5.81 & Nuclear \\
\hline HSP2O-26 & VIT_13s0019g02780.t01 & 456 & 13 & $4,015,394-4,016,080$ & 151 & 17.02 & 5.8 & Nuclear \\
\hline HSP2O-27 & VIT_13s0019g02820.t01 & 456 & 13 & $4,036,190-4,036,907$ & 151 & 17.12 & 5.81 & Nuclear \\
\hline HSP2O-28 & VIT_13s0019g02840.t01 & 456 & 13 & $4,043,383-4,044,010$ & 151 & 17.09 & 5.54 & Nuclear \\
\hline HSP2O-29 & VIT_13s0019g02850.t01 & 456 & 13 & $4,048,636-4,049,360$ & 151 & 17.05 & 5.8 & Nuclear \\
\hline HSP2O-30 & VIT_13s0019g02920.t01 & 411 & 13 & $4,108,657-4,109,160$ & 136 & 15.27 & 5.7 & Cytoplasmic \\
\hline HSP2O-31 & VIT_13s0019g02930.t01 & 483 & 13 & $4,112,675-4,113,430$ & 160 & 18.17 & 6.78 & Cytoplasmic \\
\hline HSP2O-32 & VIT_13s0019g03000.t01 & 483 & 13 & $4,149,244-4,149,995$ & 160 & 18.15 & 7.93 & Cytoplasmic \\
\hline HSP2O-33 & VIT_13s0019g03010.t01 & 435 & 13 & $4,151,427-4,155,706$ & 144 & 16.37 & 9.21 & Cytoplasmic \\
\hline HSP2O-34 & VIT_13s0019g03050.t01 & 498 & 13 & $4,180,057-4,183,444$ & 165 & 19.23 & 6.46 & Cytoplasmic \\
\hline HSP2O-35 & VIT_13s0019g03090.t01 & 483 & 13 & $4,195,524-4,196,187$ & 160 & 18.17 & 5.43 & Cytoplasmic \\
\hline HSP2O-36 & VIT_13s0019g03160.t01 & 483 & 13 & $4,227,250-4,227,937$ & 160 & 18.02 & 7.94 & Cytoplasmic \\
\hline HSP2O-37 & VIT_13s0019g03170.t01 & 480 & 13 & $4,234,111-4,234,852$ & 159 & 18.19 & 6.17 & Nuclear \\
\hline HSP2O-38 & VIT_14s0128g00280.t01 & 750 & 14 & $2,945,472-2,949,352$ & 249 & 26.84 & 5.82 & - \\
\hline HSP2O-39 & VIT_16s0022g00510.t01 & 627 & 16 & $11,604,847-11,606,213$ & 208 & 23.74 & 5.61 & Mitochondrial \\
\hline HSP2O-40 & VIT_16s0098g01060.t01 & 684 & 16 & $21,339,160-21,340,093$ & 227 & 25.03 & 6.35 & Chloroplast \\
\hline HSP2O-41 & VIT_18s0072g00490.t01 & 1098 & 18 & $19,691,814-19,692,987$ & 365 & 40.59 & 4.68 & - \\
\hline HSP2O-42 & VIT_18s0089g01270.t01 & 561 & 18 & $29,188,982-29,189,738$ & 186 & 21.13 & 5.89 & Cytoplasmic \\
\hline HSP2O-43 & VIT_19s0014g05050.t01 & 579 & 19 & $5,376,784-5,377,821$ & 192 & 22.39 & 5.35 & Cytoplasmic \\
\hline HSP2O-44 & VIT_19s0085g01050.t01 & 441 & 19 & $23,631,036-23,631,743$ & 146 & 16.44 & 5.9 & Cytoplasmic \\
\hline HSP2O-45 & VIT_18s0001g01570.t01 & 492 & 18_random & $2,135,300-2,136,089$ & 163 & 18.28 & 6.33 & Nuclear \\
\hline HSP2O-46 & VIT_18s0001g01610.t01 & 480 & 18_random & $2,183,110-2,184,273$ & 159 & 18 & 5.74 & Nuclear \\
\hline HSP2O-47 & VIT_00s0707g00010.t01 & 411 & unknow & $34,510,489-34,511,388$ & 136 & 15.69 & 4.89 & Nuclear \\
\hline HSP2O-48 & VIT_00s0992g00020.t01 & 411 & unknow & $37,397,842-37,398,790$ & 136 & 15.7 & 5.01 & Nuclear \\
\hline
\end{tabular}




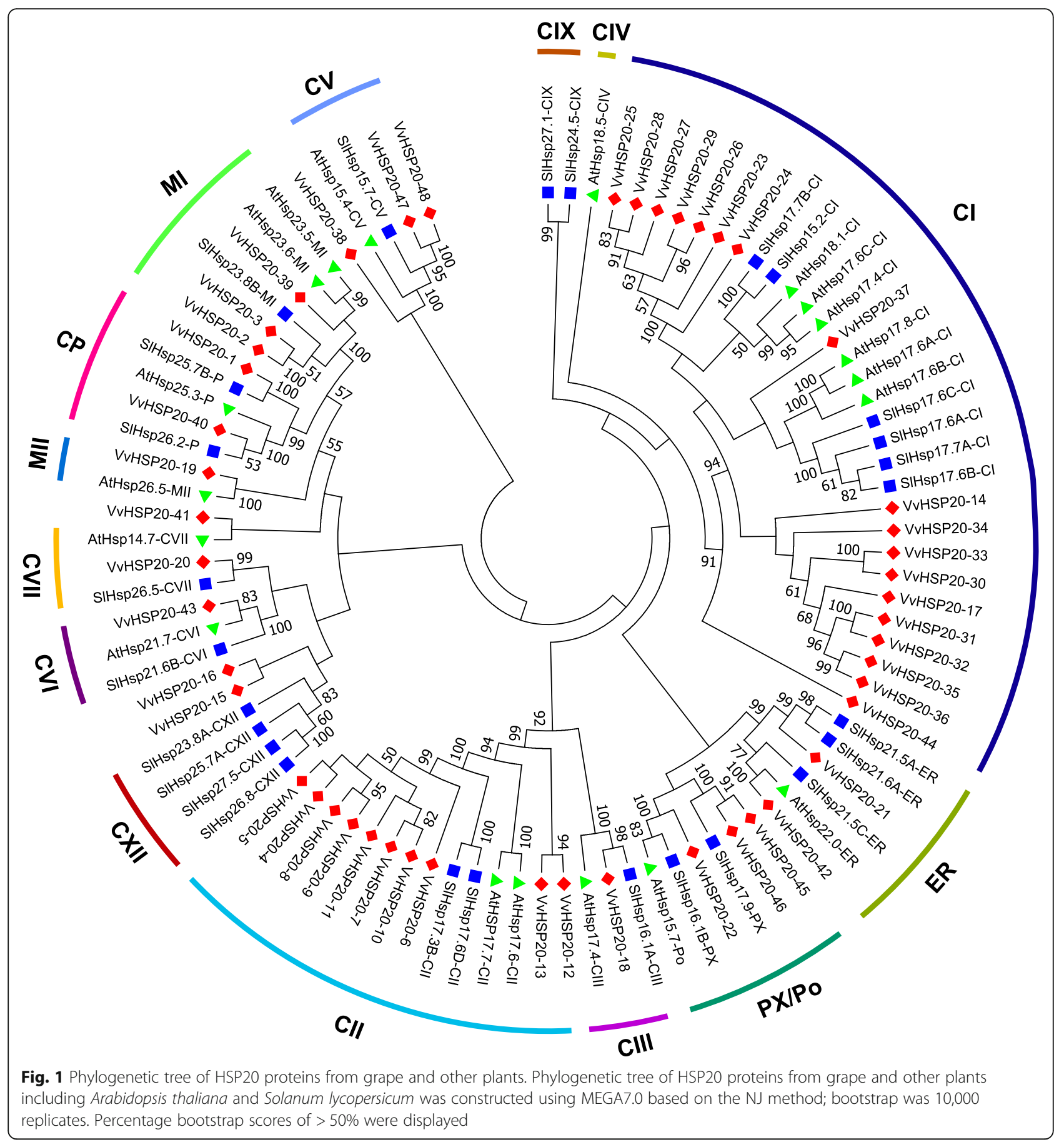

had the same motif, which indicated that they were highly conserved.

Next, we analyzed gene structure in order to better understand HSP20s. Among the VvHSP2Os genes, 24 (50.0\%) were intronless, and 21 genes $(43.8 \%)$ possessed one intron. VvHSP2O-38 (2 introns), VvHSP20-34 (3 introns), and $V v H S P 20-20$ (5 introns) had two or more introns (Fig. 2c). Genes of the same subgroup had the same intron phase, which indicated that the structure was quite conserved over evolution.

Chromosomal location and gene duplication of VvHSP2O The $48 V v H S P 20$ genes were distributed on 12 grape chromosomes (Fig. 4). Most of the VvHSP20 genes were present on chromosome 4 (10 genes) and chromosome 13 (16 genes), while each of the remaining 10 


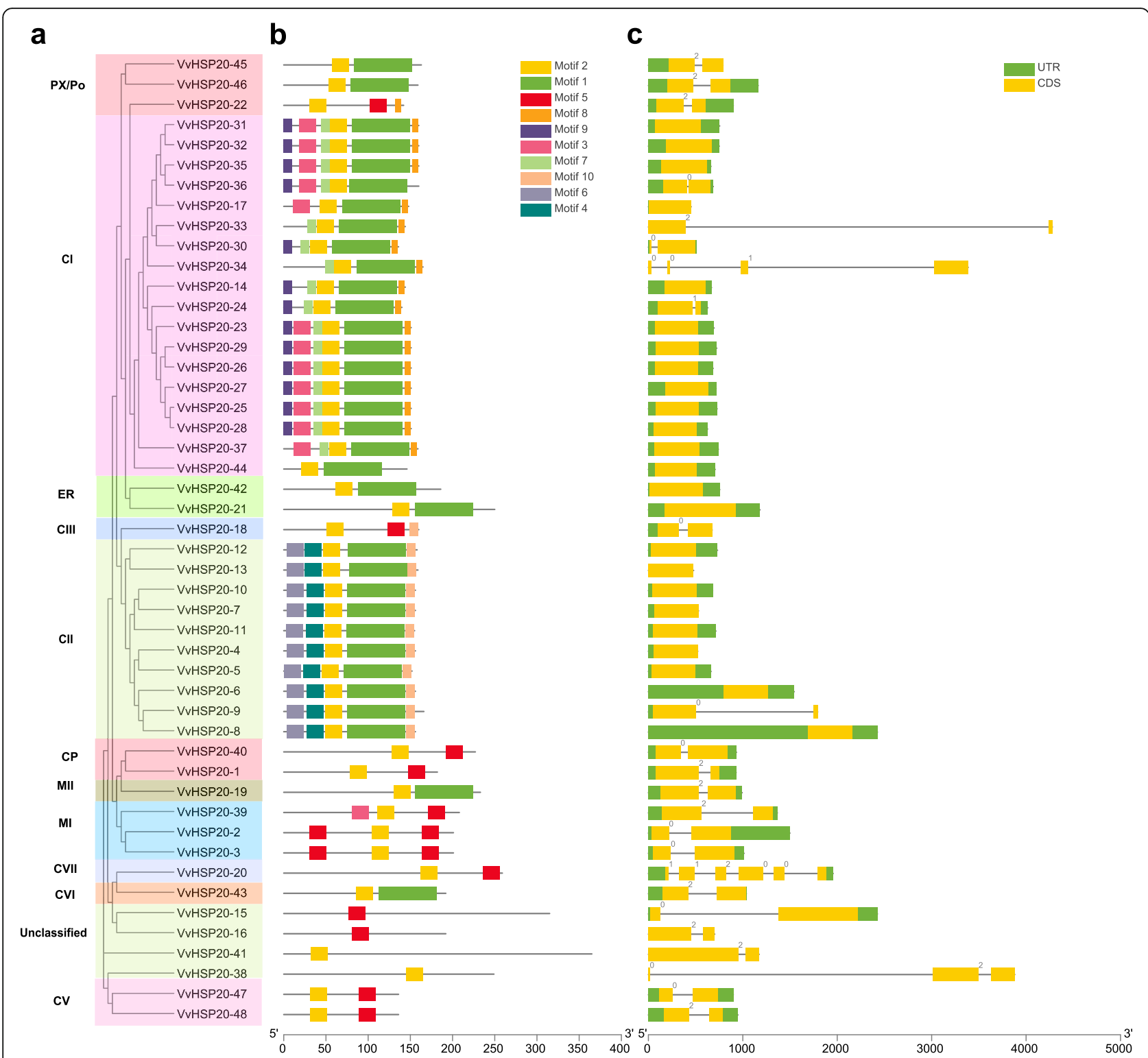

Fig. 2 Phylogenetic tree, gene structure and domain analyses of VvHSP20s. a Phylogenetic tree of VvHSP2Os was constructed with clustalx software. $\mathbf{b}$ Domain analyses of VVHSP20 proteins. Different color boxes represented the different types of motifs. c Gene structure of VvHSP20s. CDS sequences are represented by yellow round-corner rectangles and introns by grey lines, UTRs are shown with green boxes

chromosomes had one or two genes. Both tandem and segmental duplication contribute to the production of gene families during the process of evolution. Thus, potential duplication events of $V v H S P 20$ genes were analyzed. In total, four groups of $V v H S P 20$ genes (VvHSP20-2, 3; VvHSP2O-4, 5, 6, 7, 8, 9, 10, 11; VvHSP20-23, 24, 25, 26, 27, 28, 29, 30, 31, 32, 33, 35, 36 and $V v H S P 20-47,48)$ were identified as tandem duplication genes (Additional file 1: Figure S1). Furthermore, none of the genes were suggested to be products of segmental duplication. Based on the above results, we inferred that tandem duplication played an important role in the expansion of the $V v H S P 20$ family in grape.

\section{Analysis of cis-element in VvHSP2O gene promoters}

To understand the possible role of cis-regulatory elements of $V v H S P 20$, the promoter sequences (comprising - $2000 \mathrm{bp}$ upstream of the translation start site) of $48 \mathrm{VvHSP2O}$ genes were submitted into PlantCARE to detect the cis-elements. Three categories of cis-elements, including phytohormone responsive, abiotic and biotic stress-responsive, and plant development-related cis-elements were identified and are shown in Fig. 5. Among the three categories of cis-elements, the phytohormone responsive category accounts for the highest proportion. In this category, cis-acting elements were widely present in the promoter region, including auxin responsive (TGA-element and AuxRR-core), gibberellin- 
Table 2 Motif sequences identified by MEME tools

\begin{tabular}{lll}
\hline Motif & Length (aa) & Sequence \\
\hline 1 & 70 & VEEGRILQISGDRSVEKEEKNDKWHRVERSSGKFMRRFRLPENVKVDEVKAAMENGVLTVTVPKAEVQKP \\
2 & 21 & DWKETPEAHVFKADLPGLKKE \\
3 & 21 & NNMFDLWDPFQDFPFTGGALS \\
4 & 21 & KSVSAPTRTYVRDAKAMAATP \\
5 & 21 & MIDIDGISAGYEDGVLTVTVP \\
6 & 21 & MMGFDSPLFSALQHMLDATDD \\
7 & 11 & GETSAFANTRI \\
8 & 8 & VKAIDISG \\
9 & 11 & MSLIPSFFGGR \\
10 & 11 & KKPKTIEVKIA \\
\hline
\end{tabular}

responsive elements (GARE-motif, P-box, and TATC-box), ethylene-responsive (ERE), MeJA-responsive (TGACGmotif and CGTCA-motif), abscisic acid-responsive (ABRE), and salicylic acid-responsive (TCA-element). Among these elements, ABRE and ERE accounted for the largest part of the phytohormone responsive category. In the abiotic and biotic stress-responsive category, stress response-related ciselements, such as HSE1 (heat stress), WUN motif (woundresponsive element), TC-rich repeats (stress response), LTR (low temperature-responsive), ARE (anaerobic induction), and GC-motif (anoxia) were detected. In the last category, plant development-related elements, including meristem expression (CCGTCC-box and CAT-box), circadian, zein metabolism regulation (O2-site), cell cycle regulation (MSAlike), differentiation of the palisade mesophyll cells (HD-Zip 1 ), and endosperm expression (AACA_motif and GCN4 motif) were identified. In addition, most of the VvHSP2O genes possessed W boxes and MYB binding sites, including CCAAT-boxes.

\section{Expression patterns of $\mathrm{VvHSP2Os}$ in response to $\mathrm{H}_{2} \mathrm{O}_{2}$ treatment}

There is a close relationship between gene expression and function. To determine the functions of $V v H S P 20 \mathrm{~s}$ in grape, a heatmap of $47 V v H S P 20$ genes was constructed using FPKM values from RNA-Seq data in

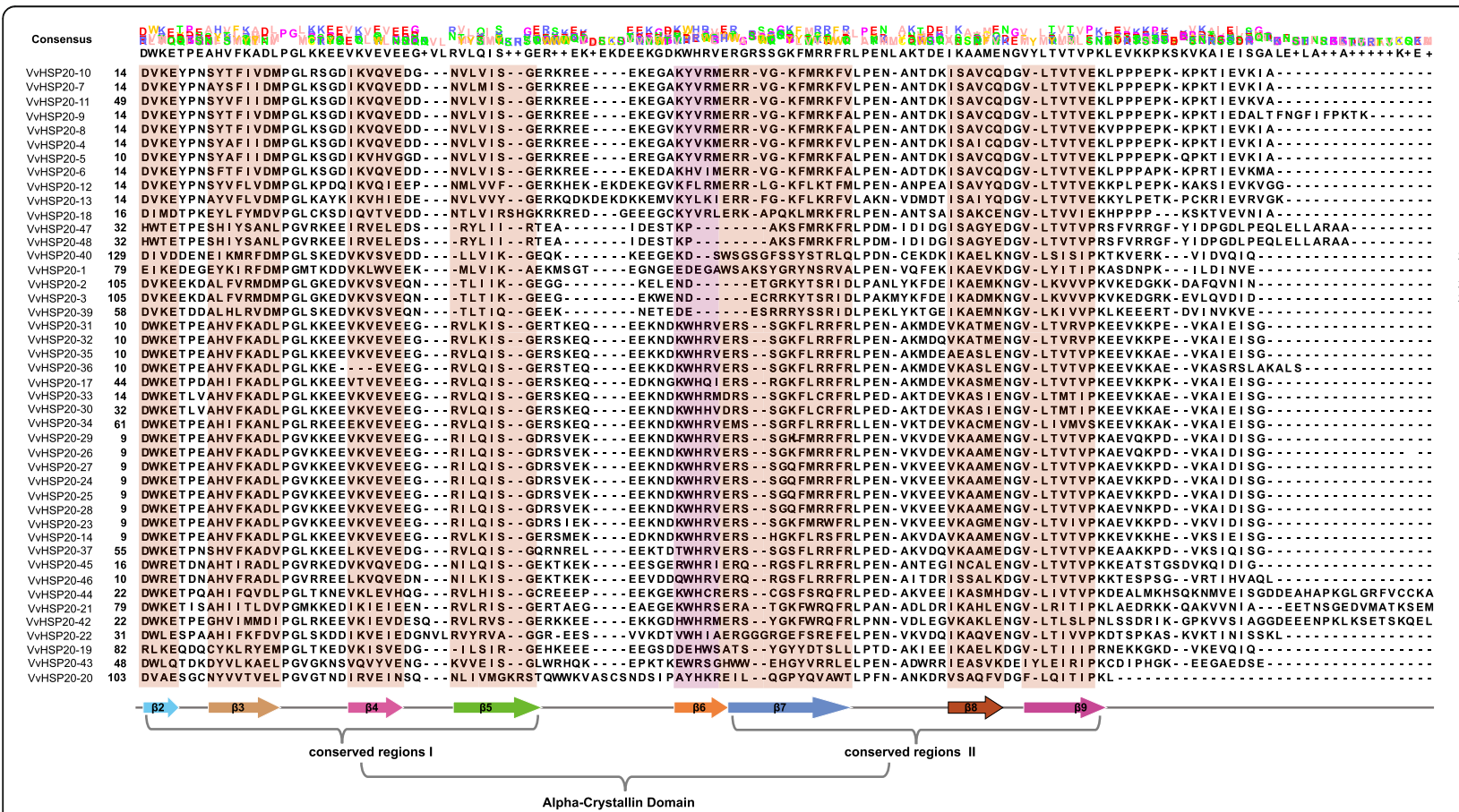

Fig. 3 The alignment of ACDs of HSP20s in grape. Names of all members are shown on the left side of the figure. Each predicted $\beta$-plated sheet is shown for shadow. The primary structure of the ACD, including the conserved regions I (CRI), II (CRII), and $\beta$ 6-loop, is shown at the bottom of the figure 


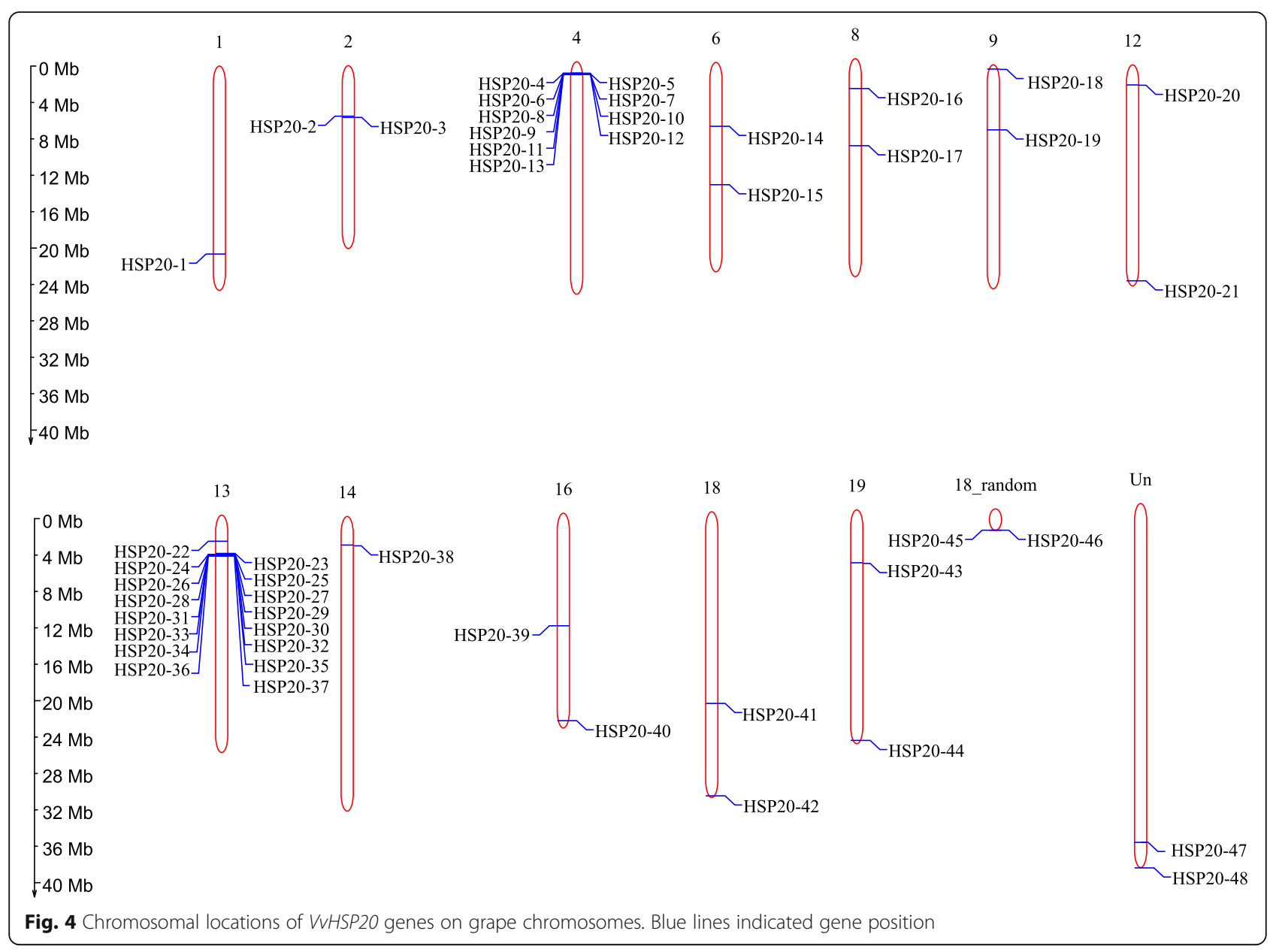

control and $\mathrm{H}_{2} \mathrm{O}_{2}$-treated berries of 'Kyoho' (Fig. 6, sampling period is described in Materials and Methods and Table 3). The expression level of HSP2O-33 was extremely low and not detected by RNA-Seq analysis during fruit development. Most VvHSP20s were downregulated after treatment, especially at the fourth period. However, the opposite trend was also observed for a few genes, including HSP2O-13, HSP20-20, and HSP20-30. These results indicated that most of the VvHSP2O genes responded to $\mathrm{H}_{2} \mathrm{O}_{2}$ treatment, and the response mechanisms of different $V v H S P 2 O$ genes to $\mathrm{H}_{2} \mathrm{O}_{2}$ were different.

Based on the statistical significance of the gene expression levels from the RNA-Seq analysis and the partitioning of the clusters of genes from the phylogenetic analysis, 14 differentially expressed $V v H S P 20$ genes were selected to be further validated by qRT-PCR in response to control and $\mathrm{H}_{2} \mathrm{O}_{2}$ treatment (Fig. 7). Consistent with the RNA-Seq data, the expression level of most genes decreased after the treatment. Besides HSP20-31, the relative expression levels of the remaining 13 genes were extremely down-regulated at the fourth period. It is worth noting that VvHSP20-17 and VvHSP20-25 were hardly expressed after treatment. Similar expression patterns were revealed within the tandem duplicated gene groups (VvHSP2O-25 and VvHSP2O-28). The similar expression patterns indicated that the tandem duplicated $V v H S P 20$ genes had similar functions and structures. Members of the CI subgroup (VvHSP20-24, VvHSP2O-25, $V v H S P 20-28$, and $V v H S P 20-31$ ) had similar expression patterns after the treatment, which suggested that they had similar functions in response to $\mathrm{H}_{2} \mathrm{O}_{2}$ treatment.

\section{Expression patterns of $A B A-r e l a t e d$ genes in response to $\mathrm{H}_{2} \mathrm{O}_{2}$ treatment}

It is well known that ABA plays an important role in grape $[23,24]$. In the previous study [1], $\mathrm{H}_{2} \mathrm{O}_{2}$ treatment was shown to promote the early fruit ripening of 'Kyoho'. To further explore the role of ABA in this process, RNA-Seq and qRT-PCR were performed to examine the expression analysis of ABA-related genes. As shown in Fig. 8, the expression patterns of the ABA synthesis-related gene (NCED3) and degradation-related gene (CYP707A4) were different following $\mathrm{H}_{2} \mathrm{O}_{2}$ treatment. Compared with the control, the expression level of NCED3 reached the highest level at veraison (H3 stage), then decreased at the H4 stage. On the 


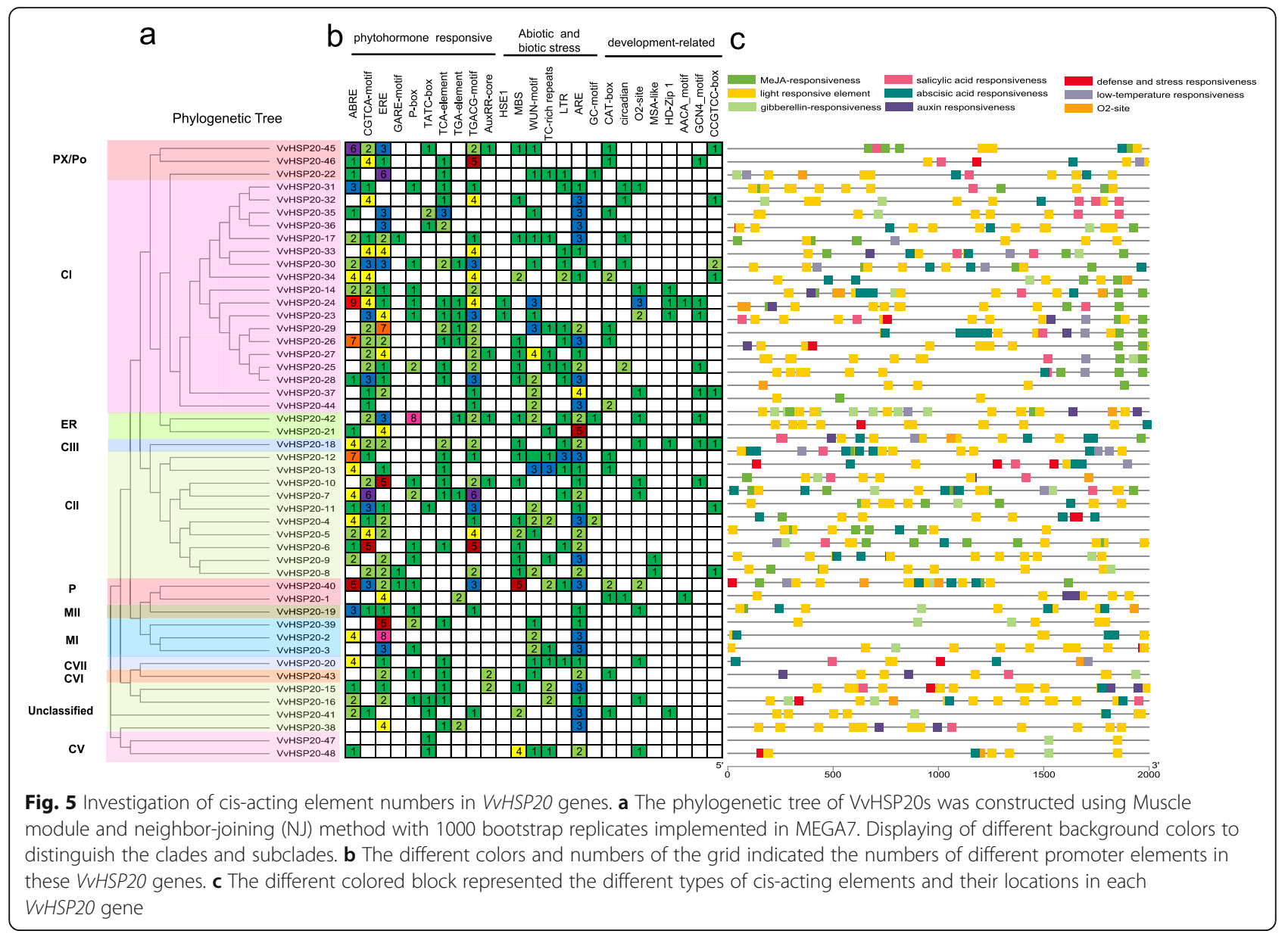

contrary, the expression level of the CYP707A4 gene increased rapidly after treatment and reached its lowest level at veraison. The changes in the expression levels of ABArelated genes indicated that $\mathrm{H}_{2} \mathrm{O}_{2}$ may regulate fruit development possibly through control of ABA catabolism and biosynthesis.

\section{Discussion}

Fruit ripening is known to be regulated by a balance between reactive oxygen species (ROS) formation and detoxification by antioxidant enzymes [25, 26]. ROS causes senescence by accumulation of superoxide anion $\left(\mathrm{O}_{2}{ }^{-}\right)$and hydrogen peroxide $\left(\mathrm{H}_{2} \mathrm{O}_{2}\right)$ during fruit ripening [3]. $\mathrm{H}_{2} \mathrm{O}_{2}$ not only acts as a stress inducing factor, but also as a signaling molecule. Imbalance between ROS generation and removal can lead to oxidative stress in aerobic organisms [27, 28]. Previous studies on $\mathrm{H}_{2} \mathrm{O}_{2}$ signaling have identified a number of genes that are regulated by $\mathrm{H}_{2} \mathrm{O}_{2}$ levels $[29,30]$. Among $\mathrm{H}_{2} \mathrm{O}_{2}$-inducible genes, HSPs are related to defense or stress responses [5]. However, the relationship between $\mathrm{H}_{2} \mathrm{O}_{2}$ and HSP2O in grape berry development is not clear. Therefore, a preliminary study on this issue was conducted.
HSP20 proteins as molecular chaperones play an important role in plant growth and development, and deter or reduce the irreversible aggregation of denatured proteins under stress $[14,15]$. Although HSP20s block the aggregation and stabilization of non-natural proteins in an ATPindependent manner [17], HSP20s themselves could not refold non-native proteins. Pea Hsp18.1 had to work with the hsp70 system to refold thermally-modified proteins [31]. In recent years, due to the availability of whole genome sequences, HSP20 families have been identified from plants, such as Arabidopsis [11], tomato [32], rice [19], and soybean [22]. However, there are few studies on the HSP20 family in grapes.

Following an integrated approach to detect HSP20s in grape, 48 putative $V v H S P 20$ genes were identified. These genes were divided into 11 subgroups (CI, CII, CIII, CV, CVI, CVII, MI, MII, ER, CP, and PX/Po). Previous research showed that 12 HSP2O gene subgroups were identified from Arabidopsis (CI-CVII, MI, MII, ER, CP, and PX/Po) [11, 33]. Likewise, four new nuclear subgroups from rice (CVIII, CIX, CX, and CXI) were reported [9]. However, several subgroups including CIV, CVIII, CIX, CX, and CXI of rice were not identified from the $V v H S P 20$ genes of grape. One 


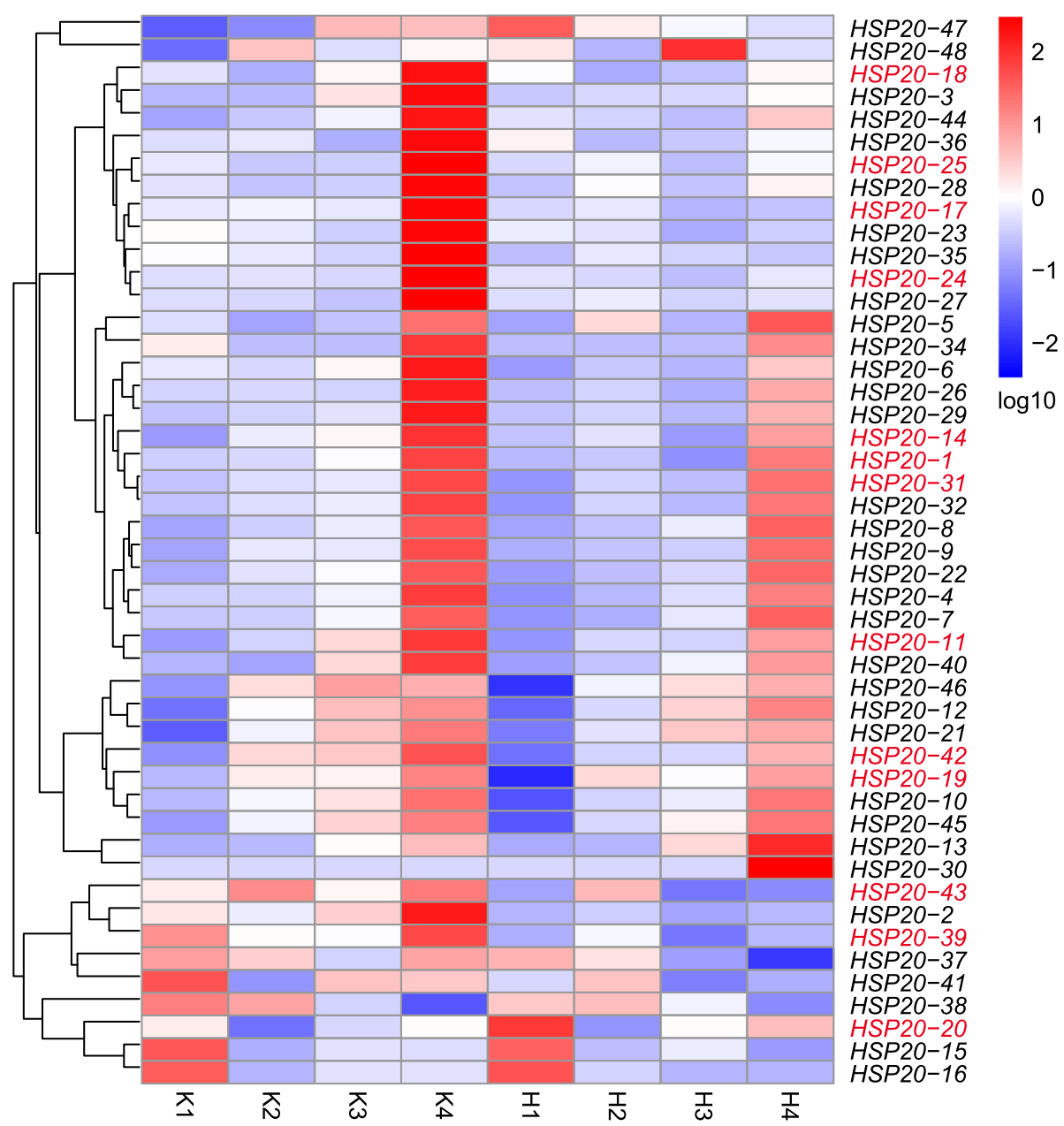

Fig. 6 Relative transcriptional expression levels of VVHSP2O from RNA-seq data in the $\mathrm{H}_{2} \mathrm{O}_{2}$ treatment and the control. Data were plotted after the Z-score normalization across the row based on absolute FPKM values of each gene at different development stages. The colors vary from blue to red representing the scale of the relative expression levels. ID in Red indicate genes selected for qRT-PCR analysis

study demonstrated that the CIV subgroup may be involved in coping with diverse stress conditions and may be developmentally regulated [33]. Under normal growth conditions, members of the CVIII subgroup may be heatinduced, while the CX subgroup of genes may be related to specific housekeeping functions [9]. Interestingly, in pepper plants, the HSP20 CIV, CV, CVIII, CIX, CX, and CXI subgroups were found to be absent [18]. In addition, the HSP20 family of rice lacked CIV and CVII subgroups [9].

Table 3 The sampling date of grape berries in this study

\begin{tabular}{llll}
\hline $\begin{array}{llll}\text { Development } \\
\text { stage }(\mathrm{dpa})\end{array}$ & $\begin{array}{l}\text { Sampling } \\
\text { time }\end{array}$ & & Code \\
\cline { 4 - 4 } & & control & Treated \\
\hline 35 & 6.12 & $\mathrm{~K} 1$ & $\mathrm{H} 1$ \\
45 & 6.21 & $\mathrm{~K} 2$ & $\mathrm{H} 2$ \\
55 & 7.1 & $\mathrm{~K} 3$ & $\mathrm{H} 3$ \\
65 & 7.12 & $\mathrm{~K} 4$ & $\mathrm{H} 4$ \\
\hline
\end{tabular}

dpa: Days post anthesis
Therefore, it was easy to see that gene acquisition and loss events are widespread in plant species. The absence of subgroups may be due to the loss of genes during the evolution of HSP20 genes.

Gene structure plays a crucial role in the evolution of multiple gene families. Our results showed that most of the $V v H S P 20$ genes (93.8\%) had no intron or only one intron of short length. Plants tend to retain genes without introns or with shorter introns [34]. This is consistent with previous reports from pepper [18] and tomato [32], where 97.14 and 83.33\% of HSP20 genes, respectively, have no or one short intron. Most VvHSP2Os in the CII and ER subgroups had no intron, which is consistent with orthologs in pepper, rice, and soybean $[18,19,22]$, but the gene structure (exon-intron) of the CI group in grape was different from those in these species, indicating that the intron pattern might not be well preserved among different species. In addition, the stability index of most VvHSP20 proteins was greater than or equal to 40 , indicating that most of them were unstable 


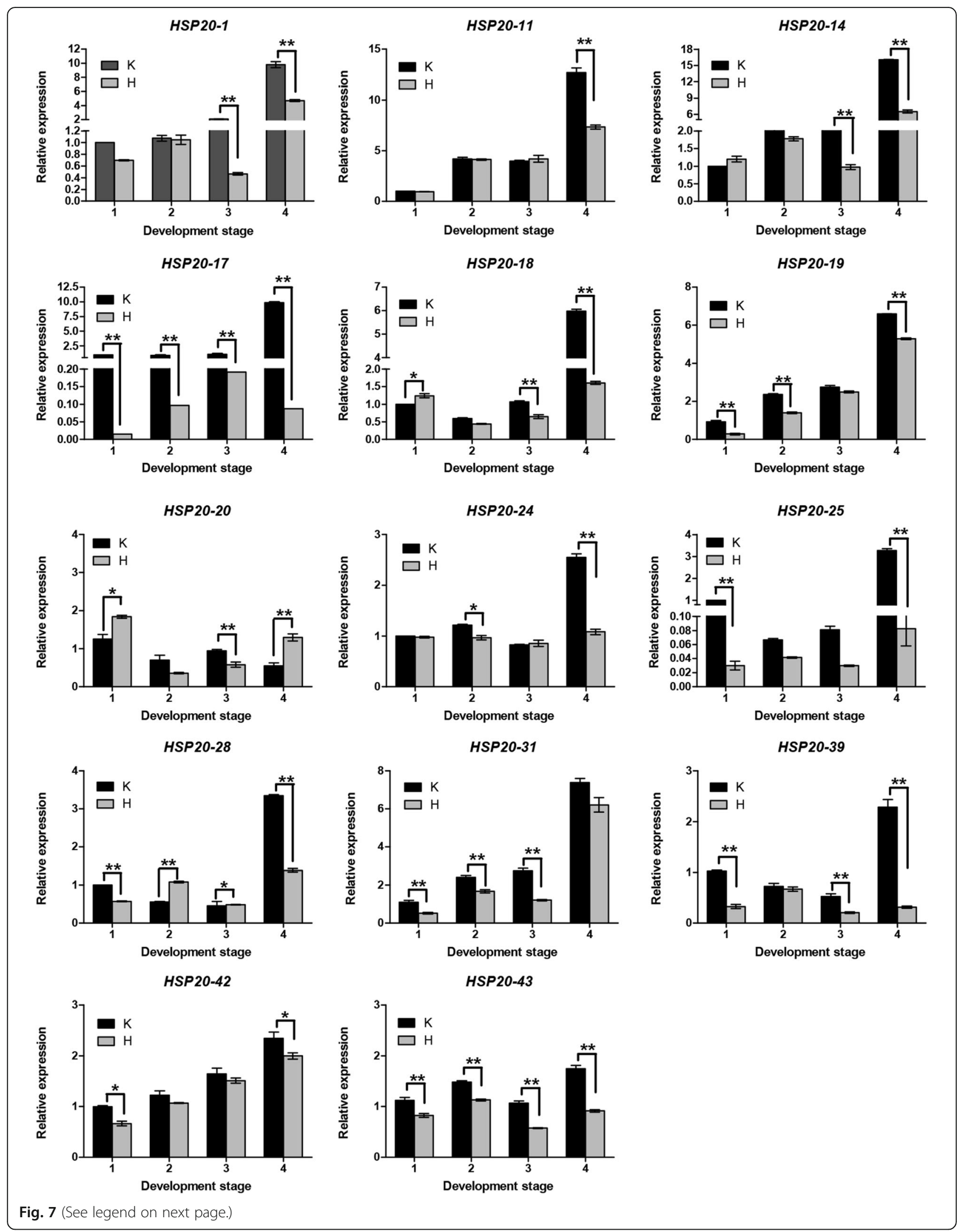


(See figure on previous page.)

Fig. 7 Expression profiles of VVHSP2Os from qRT-PCR in the $\mathrm{H}_{2} \mathrm{O}_{2}$ treatment and the control. The $x$-axis represented different sampling date, while relative expression levels for the $y$-axis. Data represented the mean of three biological replicates. Error bars represented standard deviations from three independent technical replicates. And the expression level of $\mathrm{K} 1$ was used as the calibrator. The asterisks indicate the significant level ${ }^{*} P<$ $\left.0.05,{ }^{*} P<0.01\right)$ based on a Duncan's multiple range test

proteins. Instability is believed to be a common feature of stress-responsive proteins, and may also reflect the rapid induction of $V v H S P 20$ genes [35].

The expression of heat-shock proteins (HSPs) is activated or increased under hight termperature stress, a condition in which HSP20s play important roles in protecting against protein aggregation [14]. HSP20s could be induced not only by environmental stresses, including heat, cold, drought, and salinity, but also by various developmental processes, such as embryogenesis, seed germination, and fruit ripening [22, 36-38]. In this study, the expression of VvHSP2Os was down-regulated by $\mathrm{H}_{2} \mathrm{O}_{2}$ treatment during fruit development (Fig. 7), in line with our previous research showing hydrogen peroxide can promote the early ripening of 'Kyoho' grape [1]. Similarly, FaHSP17.4 was highly expressed in leaves and flower organs of 'Fengxiang' strawberry, but the expression decreased gradually during fruit development [36]. In addition, HSP expression is induced at specific developmental stages in plants. HSP20s were highly expressed in the development stages of zygotic embryonic tissues, and during pollen maturation in rice and tomato $[9,39]$. The NJJS4 gene is a type of HSP20-coding gene, which accumulates in strawberry fruit (Fragaria $\mathrm{x}$ ananassa $\mathrm{cv}$, receptacle) during ripening [40]. Class II sHSP17.4 is expressed at almost all stages of fruit development, and maintained at a high level at the later stage of fruit ripening, while Class II sHSP17.6 reached a peak at the turning stage, and Class I HSP17.7 reached a high level at the pink stage [41]. Four differentially expressed HSP20 genes were revealed from the RNA-Seq results of tomato fruit (Heize 1706), which were considered to play an important role in fruit development [42]. These observations indicate that HSP20s are associated with fruit development.

ABA plays an important role in promoting fruit ripening. In non-climacteric grape berries, $\mathrm{ABA}$ is considered to be the main signal that triggers the onset of maturation-related processes as it peaks at version, accompanied by the beginning of berry softening and skin coloration [43]. ABA
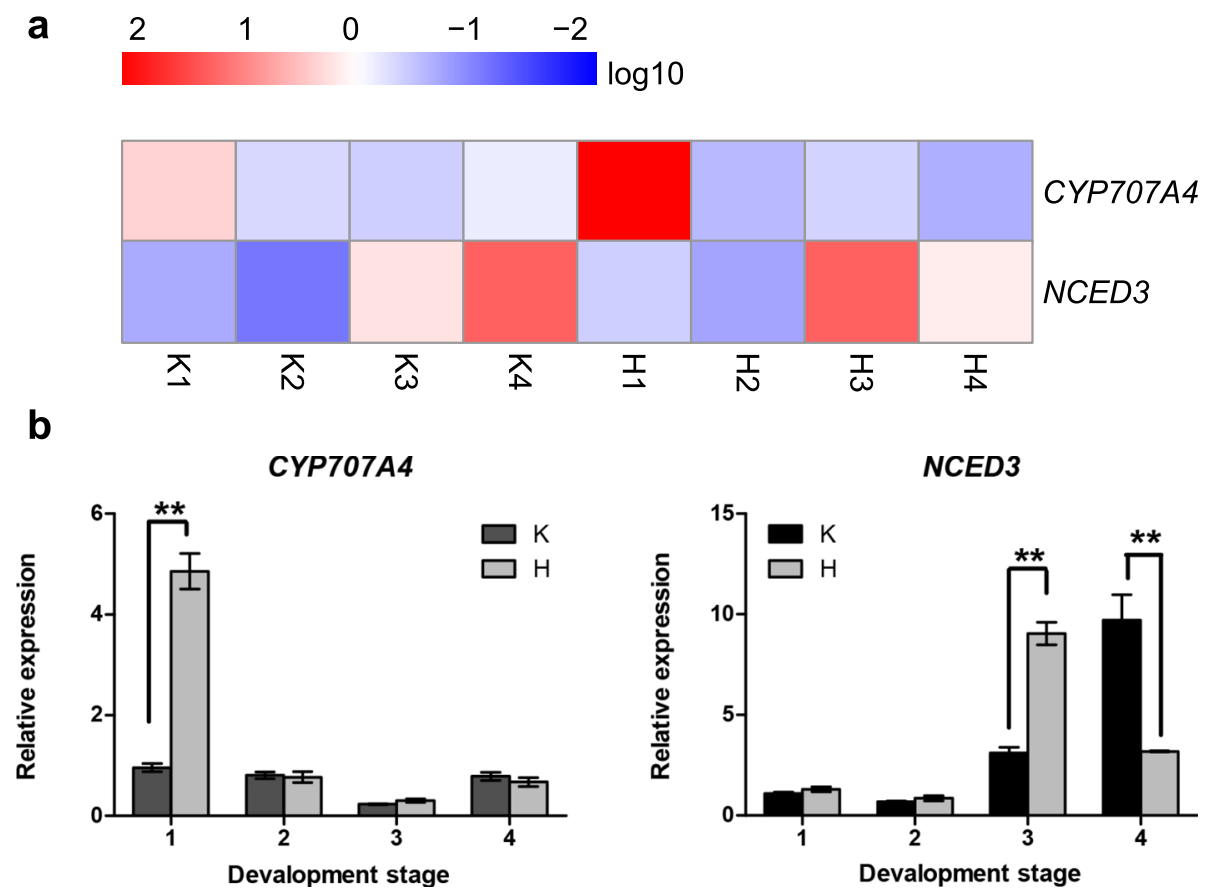

Fig. 8 Expression profiles of ABA-related genes in the $\mathrm{H}_{2} \mathrm{O}_{2}$ treatment and the control. a The expression pattern of ABA-related genes from RNAseq data. $\mathbf{b}$ Expression patterns of ABA-related genes from qRT-PCR. The $x$ axis represented different sampling dates, while the $y$ axis indicated relative expression levels. The data represent the average of three biological replicates. The error bar represents the standard deviation of three independent techniques. The expression quantity of $\mathrm{K} 1$ was used as calibrator. The asterisk indicates the significance level based on the Duncan multiple range test $\left({ }^{*} P<0.05,{ }^{*} P<0.01\right)$ 
content is determined by the dynamic balance of endogenous ABA biosynthesis and catabolism [44]. A previous study showed that 9-cis-epoxycarotenoid dioxygenase (NCED) is a key enzyme involved in ABA biosynthesis [45] and CYP707A (an key ABA degradation enzyme) plays a predominant role in ABA catabolism in vivo in strawberry $[46,47]$. NCED plays an important role in the ABAmediated signaling pathway $[45,48]$. In order to further understand the relationship between hydrogen peroxide and ABA during grape development, we analyzed the expression of ABA synthesis and degradation-related genes after $\mathrm{H}_{2} \mathrm{O}_{2}$ treatment (Fig. 8). In this study, NCED3 was found to have low expression at the early stages of fruit development, but to rapidly increase at the K4 stage in the control. However, it reached peak levels at veraison then rapidly decreased at $\mathrm{H} 4$ stage. This is consistent with changes in ABA during fruit development, whereby $\mathrm{ABA}$ reaches peak levels at the veraison stage and decreases after that $[49,50]$. ABA catabolism and biosynthesis are closely linked through feedback and feedforward loops to limit the amount of ABA needed for fruit growth and to rapidly increase the amount of $A B A$ before fruit ripening [47]. The CYP707A4 gene is highly induced at the $\mathrm{H} 1$ stage, then gradully decreases, and finally reaches the lowest values at veraison after $\mathrm{H}_{2} \mathrm{O}_{2}$ treatment. It was previously shown that the expression level of $\mathrm{FveCY}$ P707A4a was higher in the early stages of fruit development in woodland strawberry [47]. This may be due to a high level of ABA inhibiting early fruit growth [47] and accelerated $\mathrm{ABA}$ degradation following hydrogen peroxide treatment.

We propose a model for HSP20s and ABA, $\mathrm{H}_{2} \mathrm{O}_{2}$, fruit development, and high temperature (Fig. 9). Under high temperature, HSP20s are activated or increased [51]. In our study, the expression levels of most HSP2Os were down-regulated during fruit development after $\mathrm{H}_{2} \mathrm{O}_{2}$ treatment (Fig. 7) and $\mathrm{H}_{2} \mathrm{O}_{2}$ treatment promoted early ripening of 'Kyoho' grape [1]. In addition, ABA play significant roles in promoting fruit ripening and it is considered that $\mathrm{ABA}$ is the main signal triggering the beginning of maturation-related processes. ABA synthesis and metabolism were also affected by $\mathrm{H}_{2} \mathrm{O}_{2}$ (Fig. 8). Interestingly, other studies have shown that ABA induces $\mathrm{H}_{2} \mathrm{O}_{2}$ formation [52]. However, the role of HSP2Os in this process needs to be further explored.

\section{Conclusion}

In this study, the HSP2O gene family of grape was comprehensively identified. The phylogenetic relationships, gene structures, conserved motifs, and cisacting elements of $48 \mathrm{VvHSP} 20$ genes were analyzed, while the expression levels were explored by RNASeq and qRT-PCR analysis. A total of 48 HSP20 were divided into 11 subfamilies according to the

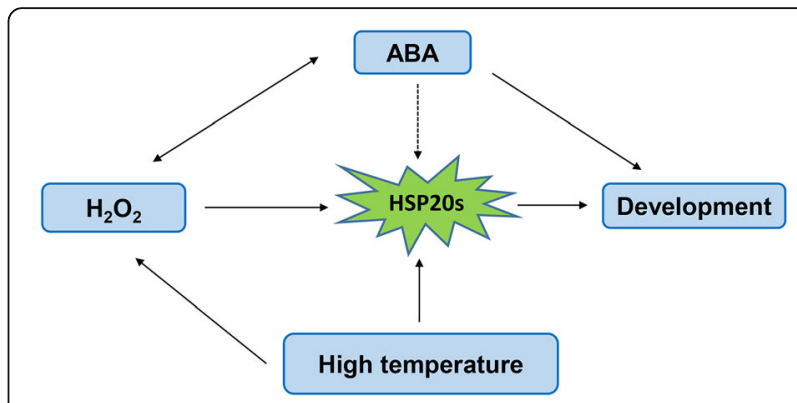

Fig. 9 Proposed Model for $\mathrm{HSP} 20$ and ABA, $\mathrm{H}_{2} \mathrm{O}_{2}$, high temperature, fruit development

phylogenetic tree and subcellular localization. The expression levels of HSP2O genes in grape under $\mathrm{H}_{2} \mathrm{O}_{2}$ treatment were verified by qRT-PCR analysis, providing a basis for further study on the functional analysis of $H S P 2 O$ genes during fruit development. Finally, the expression levels of ABA-related genes were verified. We confirmed that $\mathrm{H}_{2} \mathrm{O}_{2}$ indeed affected ABA metabolism and the expression of HSP2O genes to promote fruit development and ripening.

\section{Methods \\ Identification of HSP2O genes in grape genome}

We downloaded the grapevine reference genome assembly and protein sequences from Ensembl Plants Database (http://plants.ensembl.org/index.html). The grape HSP2O candidates were identified based on the HMM profile of HSP20 (PF00011). The CDD (https://www.ncbi.nlm.nih. gov/Structure/bwrpsb/bwrpsb.cgi), Pfam and SMART (http://smart.embl-heidelberg.de/) were used to further confirm the conserved HSP20 domain. Finally, 48 HSP20s were identified after removing the redundant sequence without the conserved ACD domain of HSP20 and with the molecular weight outside the range of $15-42 \mathrm{kDa}$. The Protparam online tools (https://web.expasy.org/protparam/) were used to predict physicochemical properties of HSP20 proteins. The online tool Protcomp (http://linux1.softberry.com/) was used to perform the subcellular localization prediction. The identified $V v H S P 20$ genes were named according to their positions on pseudomolecules [19].

\section{Phylogenetic analysis of HSP2O genes in plants}

The amino acid sequences of HSP20s derived from Arabidopsis and tomato and newly identified VvHSP20s were used for phylogenetic analysis. The neighbor joining phylogenetic tree was constructed with the default parameters based on the multiple sequence alignments of the HSP20s amino acid sequences by MEGA 7.0 software. 


\section{Characterization of the amino acid sequences and gene structure of VvHSP20s}

The conserved motifs of VvHSP20s were identified using MEME program (version 4.11.2, http://alternate.memesuite.org/tools/meme), and the parameters were as follows: optimum motif width ranges from 6 to 200 amino acid residues and maximum of 10 misfits. The structures of $V v H S P 20$ genes in grape was identified using TBtools software [53].

\section{Chromosomal location and gene duplication of HSP2O genes}

Chromosomal localization information of $V v H S P 20$ genes was obtained from Ensembl Plants Database (http://plants.ensembl.org/index.html) and the chromosome location images were generated using the MapDraw V2.1 tool (http://mg2c.iask.in/mg2c_v2.0/). The definition of CaHSP20 gene replication is based on the previous research [54]. The duplication events and syntenic analysis of VvHSP20 genes were determined using MCScanX (Multiple Collinearity Scan) [55] and Circos software, respectively.

\section{Analysis of cis-elements in VvHSP2O gene promoters}

The cis-elements were identified from the upstream $2 \mathrm{~kb}$ promoter sequences of the $V v H S P 20$ genes which were submitted to PlantCARE (http://bioinformatics.psb.ugent.be/ webtools/plantcare/html/) [56].

\section{Plant material}

Plant samples were collected from the farm of Henan University of Science \& Technology, Luoyang, China in 2017. 'Kyoho' grape treated with distilled water (containing 0.03\% silicon wet-77 surfactant) was naturally grown for 6 years as a control and treated twice with $300 \mathrm{mmol} / \mathrm{L} \mathrm{H}_{2} \mathrm{O}_{2}$. The first spraying was conducted at 25 days post anthesis (dpa) in 2017 and the second was $35 \mathrm{dpa}$. Samples were taken 35 days after flowering and every 10 days until the treated fruits were ripe (Table 2). In addition, the treated berries reached the veraison at $55 \mathrm{dpa}$. Representative pest-free samples were collected from 5 individual vines of 'Kyoho'. Thirty samples were randomly selected from each tree to record the phenological data of fruit development.

\section{RNA extraction and quantitative real-time PCR (qRT-PCR) data analysis}

The RNAprep Pure Plant Kit (TIANGEN, Beijing China) was used to isolate total RNA. cDNAs were obtained by total RNA reverse transcription using HiScript ${ }^{\oplus}$ II 1st Strand cDNA Synthesis Kit (Vazyme, Nanjing China). Primers for the VvHSP2O genes were designed by Primer Premier 5.0 software and listed in Additional file 2: Table S1. The grape ubiquitin1 gene was used as the reference gene $[57,58]$ and the expression level of $\mathrm{K} 1$ was used as the calibrator.
Quantitative real-time PCR was conducted with a total volume of $10 \mu \mathrm{L}$ of TransStart Top Green qPCR SuperMix kit (TRANSGEN, Beijing China) in CFX96 Real-Time PCR Detection System (Bio-Rad). The relative expression changes of $V v H S P 20 s$ genes were calculated using the $2^{-\Delta \Delta \mathrm{Ct}}$ method from three independent replicates [59]. SPSS version 21.0 was employed to analyze the statistical significant differences of the gene expression levels by ANOVA with Duncan's multiple range test.

The FPKM values of $V v H S P 20$ genes were from the RNA-Seq data (Accession codes, SRA: PRJNA541089). The average FPKM value of each repetition was converted to $\log 10$. Pheatmap ( $\mathrm{R}$ package) was used to generate the heatmap.

\section{Supplementary information}

Supplementary information accompanies this paper at https://doi.org/10 1186/s12870-019-2031-4.

Additional file 1: Figure S1. Syntenic relationships among VVHSP2OS genes. Different colors represent different chromosomes. Lines of different colors represent different tandem duplication genes.

Additional file 2: Table S1. Primers used for the $q R T-P C R$ reactions.

\section{Abbreviations}

ABA: Amino acid; ACD: Alpha-crystallin domain; CRI: Conserved region l; CRII: Conserved region II; HSP20s: Small heat shock proteins; PSII: Photosystem II

\section{Acknowledgements}

We would like to thank all the colleagues in our laboratory for providing useful discussions and technical assistance. We are very grateful to the editors and reviewers for their critical evaluation of the manuscript and for constructive comments on the improvement of the manuscript.

\section{Authors' contributions}

D-LG and X-RJ conceived and designed the experiments; X-RJ conduct the bioinformatics analysis and wrote the manuscript draft. $X-R J$ and P-YN examined the expression of genes by qRT-PCR. D-LG, G-HZ and Y-HY reviewed and edited the manuscript. All authors read and approved the final manuscript.

\section{Funding}

This work was financially supported by Natural Science Foundation of China (NSFC: 31672106) and Zhongyuan Science and Technology Innovation Leaders (194200510007), China. The Funding bodies were not involved in the design of the study and collection, analysis, and interpretation of data and in writing the manuscript.

\section{Availability of data and materials}

In this study, the grape genome sequence used to identify HSP20 genes were downloaded from Ensembl Plants Database (http://plants.ensembl.org/ index.html). Expression data of VVHSP2O genes in grape used in this study can be accessed via the NCBI SRA database with accession numbers of PRJNA541089 from 5th May 2020 onwards, as until then there is an embargo due to a complementary manuscript. Until then, these sequences are available from the corresponding author upon reasonable request.

Ethics approval and consent to participate Not applicable.

Consent for publication

Not applicable. 


\section{Competing interests}

The authors declare that they have no competing interests.

\section{Received: 4 July 2019 Accepted: 11 September 2019} Published online: 17 October 2019

\section{References}

1. Guo D-L, Wang Z-G, Li Q, Gu S-C, Zhang G-H, Yu Y-H. Hydrogen peroxide treatment promotes early ripening of Kyoho grape. Aust J Grape Wine Res. 2019;25:357-62.

2. Xi F-F, Guo L-L, Yu Y-H, Wang Y, Li Q, Zhao H-L, et al. Comparison of reactive oxygen species metabolism during grape berry development between 'Kyoho' and its early ripening bud mutant 'Fengzao'. Plant Physiol Biochem. 2017;118:634-42.

3. Jimenez A, Creissen G, Kular B, Firmin J, Robinson S, Verhoeyen M, et al. Changes in oxidative processes and components of the antioxidant system during tomato fruit ripening. Planta. 2002;214:751-8.

4. Chiriboga M, Giné Bordonaba J, Schotsmans W-C, Larrigaudière C, Recasens I. Antioxidant potential of 'conference' pears during cold storage and shelf life in response to 1-methylcyclopropene. Lwt-Food Sci Technol. 2013;51:170-6.

5. Königshofer H, Tromballa H-W, Löppert H-G. Early events in signalling hightemperature stress in tobacco BY2 cells involve alterations in membrane fluidity and enhanced hydrogen peroxide production. Plant Cell Environ. 2008:31:1771-80.

6. Lee B-H, Lee H-S, Won S-H, Miyao M, Chung W-I, Kim I-J, et al. Expression of the chloroplast-localized small heat shock protein by oxidative stress in rice. Gene. 2000;245:283-90

7. Banzet N, Richaud C, Deveaux Y, Kazmaier M, Gagnon J, Triantaphylidès C. Accumulation of small heat shock proteins, including mitochondrial HSP22, induced by oxidative stress and adaptive response in tomato cells. Plant J. 1998:13:519-27.

8. Neta-Sharir I, Isaacson T, Lurie S, Weiss D. Dual role for tomato heat shock protein 21: protecting photosystem II from pxidative ptress and promoting color changes during fruit maturation. Plant Cell. 2005;17:1829-38.

9. Sarkar N-K, Kim Y, Grover A. Rice sHsp genes: genomic organization and expression profiling under stress and development. BMC Genomics. 2009;10:393-411.

10. Zhao P, Wang D, Wang R, Kong N, Zhang C, Yang C, et al. Genome-wide analysis of the potato Hsp20 gene family: identification, genomic organization and expression profiles in response to heat stress. BMC Genomics. 2018;19:1-13.

11. Scharf K, Siddique M, Vierling E. The expanding family of Arabidopsis thaliana small heat stress proteins and a new family of proteins containing a-crystallin domains (Acd proteins). Cell Stress Chaperones. 2001;6:225-37.

12. Feder M-E, Hofmann G-E. Heat-shock proteins, molecular chaperones, and the stress response: evolutionary and ecological physiology. Annu Rev Physiol. 1999;61:243-82.

13. Wallace E-W-J, Kear-Scott J-L, Pilipenko E-V, Schwartz M-H, Laskowski P-R, Rojek A-E, et al. Reversible, specific, active aggregates of endogenous proteins assemble upon heat stress. Cell. 2015;162:1286-98.

14. Waters E-R. The evolution, function, structure, and expression of the plant sHSPs. J Exp Bot. 2013:64:391-403.

15. Mogk A, Bukau B. Role of sHsps in organizing cytosolic protein aggregation and disaggregation. Cell Stress Chaperones. 2017;22:493-502

16. Mani N, Ramakrishna K, Suguna K. Characterization of rice small heat shock proteins targeted to different cellular organelles. Cell Stress Chaperones. 2015:20:451-60

17. Waters E-R, Lee G-J, Vierling E. Evolution, structure and function of the small heat shock proteins in plants. J Exp Bot. 1996;47:325-38.

18. Guo M, Liu J, Lu J, Zhai Y, Wang H, Gong Z, et al. Genome-wide analysis of the CaHsp20 gene family in pepper: comprehensive sequence and expression profile analysis under heat stress. Front Plant Sci. 2015;6:806.

19. Ouyang Y, Chen J, Xie W, Wang L, Zhang Q. Comprehensive sequence and expression profile analysis of Hsp20 gene family in rice. Plant Mol Biol. 2009;70:341-57

20. Yu J, Cheng Y, Feng K, Ruan M, Ye Q, Wang R, et al. Genome-wide identification and expression profiling of tomato $\mathrm{Hsp} 20$ gene family in response to biotic and abiotic stresses. Front Plant Sci. 2016;7:1-14.

21. He Y, Fan M, Sun Y, Li L. Genome-wide analysis of watermelon HSP2Os and their expression profiles and subcellular locations under stresses. Int J Mol Sci. 2019;20:12.

22. Lopes-Caitar V-S, de Carvalho M-C, Darben L-M, Kuwahara M-K, Nepomuceno AL, Dias W-P, et al. Genome-wide analysis of the Hsp20 gene family in soybean: comprehensive sequence, genomic organization and expression profile analysis under abiotic and biotic stresses. BMC Genomics. 2013:14:577-94.

23. Sun $Y$, Liu $Q$, Xi B, Dai H. Study on the regulation of anthocyanin biosynthesis by exogenous abscisic acid in grapevine. Sci HorticAmsterdam. 2019;250:294-301.

24. Koyama K, Sadamatsu K, Goto-Yamamoto N. Abscisic acid stimulated ripening and gene expression in berry skins of the cabernet sauvignon grape. Funct Integr Genomics. 2010;10:367-81.

25. Kumar V, Irfan M, Ghosh S, Chakraborty N, Chakraborty S, Datta A. Fruit ripening mutants reveal cell metabolism and redox state during ripening. Protoplasma. 2016;253:581-94.

26. Pilati S, Brazzale D, Guella G, Milli A, Ruberti C, Biasioli F, et al. The onset of grapevine berry ripening is characterized by ROS accumulation and lipoxygenasemediated membrane peroxidation in the skin. BMC Plant Biol. 2014;14:87.

27. Vandenabeele S, Katrien V-D-K, Dat J, Gadjev I, Boonefaes T, Morsa S, et al. A comprehensive analysis of hydrogen peroxide-induced gene expression in tobacco. Proc Natl Acad Sci U S A. 2003:100:16113-8.

28. Desikan R, Mackerness AH. S, Hancock J-T, Neill S-J. regulation of the Arabidopsis transcriptome by oxidative stress. Plant Physiol. 2001;127:159-72.

29. Wang L, Guo Y, Jia L, Chu H, Zhou S, Chen K, et al. Hydrogen peroxide acts upstream of nitric oxide in the heat shock pathway in Arabidopsis seedlings. Plant Physiol. 2014;164:2184-96.

30. Desikan $\mathrm{R}$, Clarke A, Hancock J-T, Neill S-J. $\mathrm{H}_{2} \mathrm{O}_{2}$ activates a MAP kinase-like enzyme in Arabidopsis thaliana suspension cultures. J Exp Bot. 1999;50:1863-6.

31. Lee G-J, Vierling E. A small heat shock protein cooperates with heat shock protein 70 systems to reactivate a heat-denatured protein. Plant Physiol. 2000;122:189-98.

32. Yu J, Cheng Y, Feng K, Ruan M, Ye Q, Wang R, et al. Genome-wide identification and expression profiling of tomato Hsp20 gene family in response to biotic and abiotic stresses. Front Plant Sci. 2016;7:1-14.

33. Siddique M, Gernhard S, von Koskull-Döring P, Vierling E, Scharf K. The plant SHSP superfamily: five new members in Arabidopsis thaliana with unexpected properties. Cell Stress Chaperones. 2008:13:183-97.

34. Mattick J-S, Gagen M-J. The evolution of controlled multitasked gene networks: the role of introns and other noncoding RNAs in the development of complex organisms. Mol Biol Evol. 2001;18:1611-30.

35. Rao P-K, Roxas B-A-P, Li Q. Determination of global protein turnover in stressed mycobacterium cells using hybrid-linear ion trap-fourier transform mass spectrometry. Anal Chem. 2008:80:396-406.

36. Gang L, Xia Z, Lu Z, Houcheng Z. Cloning and expression analysis of small heat shock protein (FaHSP17.4) gene from strawberry fruit (Fragaria ananassa). Mol Plant Breed. 2016;14:328-36.

37. Reddy P-S, Kishor P-B-K, Seiler C, Kuhlmann M, Eschen-Lippold L, Lee J, et al. Unraveling regulation of the small heat shock proteins by the heat shock factor HvHsfB2C in barley: its implications in drought stress response and seed development. PLoS One. 2014;9:e89125.

38. Srivastava A, Gupta A-K, Datsenka T, Mattoo A-K, Avtar HK. Maturity and ripening-stage specific modulation of tomato (Solanum lycopersicum) fruit transcriptome. GM Crops. 2010;1:237-49.

39. Wehmeyer $\mathrm{N}$, Vierling $\mathrm{E}$. The expression of small heat shock proteins in seeds responds to discrete developmental signals and suggests a general protective role in desiccation tolerance. Plant Physiol. 2000;122:1099-108.

40. Medina-Escobar N, Cárdenas J, Muñoz-Blanco J, Caballero J-L. Cloning and molecular characterization of a strawberry fruit ripening-related cDNA corresponding a mRNA for a low-molecular-weight heat-shock protein. Plant Mol Biol. 1998:36:33-42.

41. Ding C, Wang C-Y, Gross K-C, Smith D-L. Reduction of chilling injury and transcript accumulation of heat shock proteins in tomato fruit by methyl jasmonate and methyl salicylate. Plant Sci. 2001;161:1153-9.

42. Arce D-P, Krsticevic F-J, Bertolaccini M-R, Ezpeleta J, Ponce S-D, Tapia E. Analysis of small heat shock protein gene family expression (RNA-Seq) during the tomato fruit maturation. IFMBE Proc. 2015;49:679-82.

43. Kuhn N, Guan L, Dai Z-W, Wu B-H, Lauvergeat V, Gomès E, et al. Berry ripening: recently heard through the grapevine. J Exp Bot. 2014;65:4543-59.

44. Leng $P$, Yuan B, Guo Y-D. The role of abscisic acid in fruit ripening and responses to abiotic stress. J Exp Bot. 2014;65:4577-88.

45. Qin X-Q, Zeevaart J-A-D. The 9-cis-epoxycarotenoid cleavage reaction is the key regulatory step of abscisic acid biosynthesis in water-stressed bean. Proc Natl Acad Sci USA. 1999:96:15354-61.

46. Kushiro T, Okamoto M, Nakabayashi K, Yamagishi K, Kitamura S, Asami T, et al. The Arabidopsis cytochrome P450 CYP707A encodes ABA 80hydroxylases: key enzymes in ABA catabolism. EMBO J. 2004;23:1647-56. 
47. Liao X, Li M, Liu B, Yan M, Yu X, Zi H, et al. Interlinked regulatory loops of ABA catabolism and biosynthesis coordinate fruit growth and ripening in woodland strawberry. Proc Natl Acad Sci U S A. 2018;115:E11542-50.

48. Fujita Y, Yoshida T, Yamaguchi-Shinozaki K. Pivotal role of the AREB/ABFSnRK2 pathway in ABRE-mediated transcription in response to osmotic stress in plants. Physiol Plant. 2013;147:15-27.

49. Davies C, BOSS P-K, Robinson S-P. Treatment of crape berries, a nonclimacteric fruit with a synthetic auxin, retards ripening and alters the expression of developmentally regulated genes. Plant Physiol. 1997;115:1155-61.

50. Wheeler S, Loveys B, Ford C, Davies C. The relationship between the expression of abscisic acid biosynthesis genes, accumulation of abscisic acid and the promotion of Vitis vinifera L. berry ripening by abscisic acid. Aust J Grape Wine Res. 2009;15:195-204.

51. Zhao P, Wang D-D, Wang R-Q, Kong N-N, Zhang C, Yang C-H, et al. Genome-wide analysis of the potato Hsp20 gene family: identification, genomic organization and expression profiles in response to heat stress. BMC Genomics. 2018:19:61.

52. Ni L, Fu X-P, Zhang H, Li X, Cai X, Zhang P-P, et al. Abscisic acid inhibits rice protein phosphatase PP45 via $\mathrm{H}_{2} \mathrm{O}_{2}$ and relieves epression of the $\mathrm{Ca}^{2+} / \mathrm{CaM}$ dependent protein kinase DMI3. Plant Cell. 2019;31:128-52.

53. Chen $\mathrm{C}$, Chen $\mathrm{H}, \mathrm{He}$ Y, Xia R. TBtools, a Toolkit for Biologists integrating various biological data handling tools with a user-friendly interface. BioRxiv. [Preprint]. 2018;289660. https://doi.org/10.1101/289660.

54. Gu Z, Cavalcanti A, Chen F, Bouman P, Li W. Extent of gene duplication in the genomes of drosophila, nematode, and yeast. Mol Biol Evol. 2002;19:256-62.

55. Wang Y, Tang H, DeBarry J-D, Tan X, Li J, Wang X, et al. MCScanX: a toolkit for detection and evolutionary analysis of gene synteny and collinearity. Nucleic Acids Res. 2012;40:e49.

56. Lescot M, Déhais $P$, Thijs $G$, Marchal $K$, Moreau $Y$, Van de Peer $Y$, et al. PlantCARE, a database of plant cis-acting regulatory elements and a portal to tools for in silico analysis of promoter sequences. Nucleic Acids Res. 2002;30:325-7.

57. Downey M-O, Harvey J-S, Robinson S-P. Synthesis of flavonols and expression of flavonol synthase genes in the developing grape berries of shiraz and chardonnay (Vitis vinifera L.). Aust J Grape Wine R. 2003;9:110-21.

58. Guo D-L, Xi F-F, Yu Y-H, Zhang X-Y, Zhang G-H, Zhong G-Y. Comparative RNA-Seq profiling of berry development between table grape 'Kyoho' and its early-ripening mutant 'Fengzao. BMC Genomics. 2016;17:795-812.

59. Schmittgen T-D, Livak K-J. Analyzing real-time PCR data by the comparative CT method. Nat Protoc. 2008;3:1101-8.

\section{Publisher's Note}

Springer Nature remains neutral with regard to jurisdictional claims in published maps and institutional affiliations.

Ready to submit your research? Choose BMC and benefit from:

- fast, convenient online submission

- thorough peer review by experienced researchers in your field

- rapid publication on acceptance

- support for research data, including large and complex data types

- gold Open Access which fosters wider collaboration and increased citations

- maximum visibility for your research: over $100 \mathrm{M}$ website views per year

At $\mathrm{BMC}$, research is always in progress.

Learn more biomedcentral.com/submissions 